\title{
Nachruf auf Wladimir Krysinski
}

\author{
DOROTHEA SCHOLL
}

Wladimir Krysinski ist am 17. September 2020 im Alter von 85 Jahren in Ottawa gestorben. Er war ein inspirierender Hochschullehrer, Forscher und Dichter. Ich lernte ihn im Sommersemester 1993 kennen, als er eine Gastprofessur am Romanischen Seminar der Universität Kiel innehatte. Zusammen mit Kollegen und Studierenden nahm ich an seinem Seminar zur Avantgarde teil. Sein weiter geistiger Horizont zog uns in den Bann. Wir mochten Wladimir. Wir waren beeindruckt von seiner Lebenserfahrung, seinem Wissen und Denken, seiner angenehm kultivierten Art, seinem spontanen Humor, seiner Neugier auf Land und Leute und seinem aufrichtigen Interesse an unserem Leben und Forschen. Sein Aufenthalt war auf fachlicher und persönlicher Ebene für uns alle eine unschätzbare Bereicherung und führte in der Folgezeit zu regelmäßigen Einladungen zu Vorträgen an unserer Universität. Angesichts seiner perfekten Beherrschung zahlreicher Sprachen und seiner regen Kongressreisen in die weite Welt nannten wir Wladimir (nach einem Ausspruch von Manfred Schmeling) unseren „polyglotten Globetrotter“.

Als Professor für Komparatistik lehrte Wladimir Krysinski an der Université de Montréal und nahm zahlreiche Gastprofessuren auf der ganzen Welt wahr. Seine Forschungen ergaben sich aus seiner Liebe zur Literatur und seinem Interesse an Philosophie und Literaturtheorie. Sie konzentrieren sich auf das Phänomen der Avantgarde; Pirandello und das Theater; das Verhältnis von Moderne und Postmoderne; Roman und Erzähler; die Frage nach der Weltliteratur. Für jedes dieser Gebiete ist Wladimir Krysinski als führender Spezialist weltweit anerkannt. Carrefours de signes - Essais sur le roman moderne (1981), Il romanzo e la modernità (2003), Dialéticas da Transgressão (2007) gehören zu den bedeutsamsten Romananalysen der Moderne und sind maßgebende Ausgangspunkte zahlreicher Studien zum Roman. Le paradigme inquiet. Pirandello et le champ de la modernité (1989) war wegweisend für die Pirandellound Theaterforschung bis in unsere Gegenwart.

Die Überzeugungskraft von Wladimir Krysinskis gesamter Forschung verdankt sich der Nuanciertheit, Differenziertheit und dem Gedankenreichtum seiner Analysen und seinen profunden Kenntnissen der Weltliteratur, der Philosophie und der Literaturtheorie. Diese Kenntnisse gestatteten ihm, mit 
außergewöhnlicher Perspektivenvielfalt, Umsichtigkeit und Ausgewogenheit Einseitigkeiten $\mathrm{zu}$ relativieren und das interdisziplinäre und interkulturelle Verständnis zu fördern. Sie erlaubten ihm, die Relevanz von Theorien anhand der Originaltexte der Weltliteratur zu überprüfen und $\mathrm{zu}$ hinterfragen und die verschiedenen Ausrichtungen des kritischen sowie des literarischen Diskurses $\mathrm{zu}$ erfassen und zu vermitteln. Wladimir Krysinskis vergleichende Literaturwissenschaft ist immer auch Auseinandersetzung und Vermittlung mit anderen Disziplinen wie Linguistik, Psychologie, Soziologie, Philosophie. Diese Art von Komparatistik eröffnet nuancierte Perspektiven auf die Vielfalt von Weltanschauungen und ihrer Entstehungsbedingungen. Sie erschließt das Verständnis für nationale und kulturelle Eigenarten und erhellt die Bedeutung, Tradierung und Verbreitung literarischer Themen in Geschichte und Gegenwart.

Besonders aufschlussreich ist in diesem Zusammenhang auch seine Weiterführung der Fragestellung „Was ist Literatur?“ und des Begriffs der „Weltliteratur" (Goethe) angesichts der sich verändernden Kommunikationsprozesse in der Epoche der Globalisierung; seine Frage nach dem Kanon angesichts der Medien; sein Fragen nach der Rolle, der Lebensfähigkeit, dem Stellenwert und dem Wert von Literatur als Ausdruck des Menschen im Verhältnis zu seinen Mitmenschen und seiner Umwelt angesichts der Komplexität unserer Zeit.

Als Schriftsteller, der seine literarischen Werke in verschiedenen Sprachen schrieb und publizierte (u.a. französisch, englisch, italienisch) - seine letzte Gedichtsammlung Poematy i Wspomnienia (2018) erschien in seiner Muttersprache polnisch; als Komparatist, der mindestens acht Sprachen perfekt beherrschte und in diesen auch publizierte (u.a. polnisch, russisch, französisch, englisch, italienisch, spanisch, portugiesisch, deutsch), war er sowohl Vermittler zwischen Ost- und Westeuropa wie auch zwischen Europa und dem amerikanischen Kontinent. Wladimir Krysinskis Schriften fördern nicht nur die weltweite Kommunikation und Transparenz zwischen verschiedenen Sprachen, Literaturen, Forschungsdisziplinen und Kulturen, sie sind auch Zeugnisse eines nachdenklichen Menschen mit wachem Geist, der seinen Mitmenschen gegenüber aufgeschlossen und zugetan war.

\section{Dorothea Scholl}

dscholl@romanistik.uni-kiel.de

Kiel University

GERMANY 